\author{
Military Technical College \\ Kobry El-Kobbah, \\ Cairo, Egypt
}

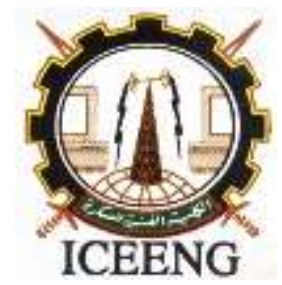

\title{
OTT VoIP over LTE vs. VoLTE End-to-End QoS using OPNET
}

\author{
Ashraf D. Elbayoumy*, Mohamed Hussein*, and Salah F. Al-Ashry*
}

\begin{abstract}
Long Term Evolution (LTE) is a totally IP based cellular network, that only supports packet switching (PS) function, previous cellular networks, such as $2 \mathrm{G}$ and $3 \mathrm{G}$, were basically designed to carry voice calls through circuit switching (CS) service, then data service was supported through techniques that basically encapsulated data inside the voice-call connections. In LTE there are many alternatives for offering voice services over LTE to ensure the service continuity over celluar networks, these alternatives include Voice over LTE (VoLTE), also include Over the Top Voice over IP (OTT VoIP) one of the proposed alternatives for voice service over LTE, which is the lowest in cost and complexity. The objective of this paper is, to investigate the quality of the low cost OTT VoIP voice service, as an alternative to VoLTE, especially for those Mobile Network Operators (MNOs), who aren't ready to deploy the highly complex and costly IP Multimedia Subsystem (IMS) infrastructure of VoLTE .

Performance evaluation for OTT VoIP over LTE, compared with VoLTE is provided, from the most important QoS parameters point of view, in different scenarios with different number of users assuming congested and non-congested network states, the analysis for all these scenarios are based on simulations using OPNET 17.5 simulation tool, the results provide a performance template for MNOs who doesn't want to deploy IMS and doesn't have legacy 2G/3G networks.
\end{abstract}

Keywords: VoLTE; OTT VoIP; OPNET; IMS

\section{INTRODUCTION}

Due to the dominance of the packet switching compared with the circuit switching in the field of telecommunications, this fact became clear and evident in the Internet, the largest packet switching information network, that was the main motivation behind the thinking in the integration of mobile networks with the Internet, this idea was behind the development of LTE; the last step towards the 4th generation of cellular networks that gained paramount importance.

* Egyptian Armed Forces. 
Since LTE by design doesn't have a Circuit Switched (CS) core for voice service, that will remain the most important service delivered by operators of cellular networks, which means that even the voice calls have to be routed through the packet switched network, the Voice Over LTE (VoLTE) is considered as the long-term voice mean for the voice services delivery on LTE networks [2] which is a special type of VolP designed to meet the LTE standard and based on the IP Multimedia Subsystem network (IMS) infrastructure, where the voice packets are QoS differentiated by the whole LTE network. But on the other hand, IMS is complex, costly and will take long time for deployment [3] from some network operators' point of view.

There is also Over the Top VoIP (OTT VoIP) like "Skype" and "Google Talk" etc. This sometimes called "Third party VoIP" as one of the suggested intermediate solutions for voice service on LTE, which is a very simple solution with very little cost for network operators, where the voice packets don't have any special treatment or advantage over any other data packets in LTE. Nonetheless, even in the presence of VoLTE, OTT VoIP will be widely used by users as an alternative, because of the fact that it enables them to choose their own voice service, [4] in addition to the flexibility of making calls to others using VoIP services over Internet, which can't be accomplished by VoLTE.

LTE has a distinctive and unique Quality of Service (QoS) mechanism for end-toend delivered service in order to improve the perception of the end user about the provided voice service.

QoS in LTE, how good is the OTT VoIP for a reasonable quality and low cost voice service over LTE, as an alternative to VoLTE and how the performance will be for different LTE network states, all will be investigated during this study. The rest of the paper is organized as follows, Section II presents QoS description in LTE, section III presents the IMS different nodes and concepts behind the VoLTE technology compared with OTT VoIP technology. Simulation scenarios are presented in Section IV. Results and discussion are presented in section V, and finally a general conclusion of this work is presented in Section VI.

\section{QOS MANAGEMENT IN LTE}

\section{A. Bearers in LTE}

In LTE Network the QoS uses prioritization method for different services during the congestion in the network. In LTE, QoS is applied between User Equipment (UE) and Packet Gateway (PGW) and is applied to a set of bearers. 'Bearer' is a concept that defines the class of treatment to type of traffic. All traffic flows carried over a single bearer have the same packet treatment between the UE and the PGW.

In LTE, QoS is applied on Radio bearer, S1 bearer and S5/S8 bearer, where all of the three bearers together called as "Evolved Packet System (EPS) bearer" [5] as Fig. 1 shows. 


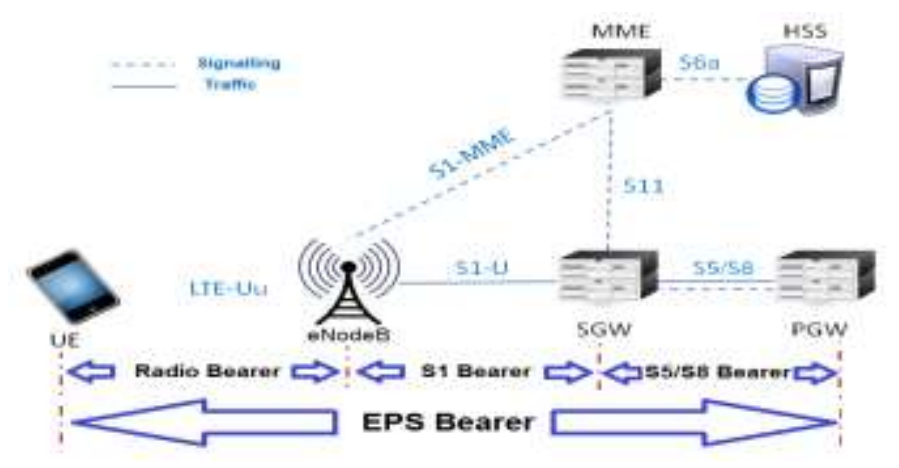

Fig. 1: Bearers across an LTE system. [4].

In The EPS bearer maps a traffic flow into a corresponding virtual logical channel between the UE and the PGW. Moreover, a radio bearer is associated with each EPS bearer as a logical channel between UE and eNodeB [6]. There exists a GPRS Tunneling Protocol (GTP) tunnel, between eNodeB and Serving Gateway (SGW) and also between SGW and PGW. Bearers are classified according to its QoS requirements as either "Default" or "Dedicated" bearers. A default bearer is NonGuaranteed Bitrate (Non GBR), it doesn't have a bit rate guarantee and offers only best-effort service. UE can have multiple default bearers, but each default bearer must have a unique IP address. A dedicated bearer is another bearer that works on top of the default bearer, by creating a dedicated tunnel to provide a special priority to specific services, and uses one of the previously established default bearers' IP address, so it doesn't have a separate IP address. A dedicated bearer moreover is categorized as guaranteed bit rate (GBR) bearer that provides guaranteed bit rate and has dedicated network resources that meet the requirement of real-time voice and video applications, or non-guaranteed bit rate (non-GBR) bearer that doesn't provide guaranteed bit rate and doesn't have dedicated resources, which can be considered sufficient for best-effort traffic.

\section{B. QoS Class Indicator (QCI)}

$\mathrm{QCl}$ specifies the way of treatment (e.g. scheduling weights, admission thresholds, queue management thresholds, link-layer protocol configuration, etc.) for the userplane traffic between the UE and the PGW. The QCl specification with related parameters and related applications are presented in [7] and is given in a Traffic Flow Template (TFT), which is always associated with dedicated bearer, it defines policies and regulations so that UE and network is aware of which IP packet should be sent on specific dedicated bearer. The TFT usually has policies on the idea of one of the following parameters [8]:

- Port numbers

- Type of Service (ToS) / Differentiated Services Code Point (DSCP) values

- Source/Destination address

- Protocol (TCP/UDP)

\section{III.VOLTE PRINCIPLES VS OTT VOIP}

The IP Multimedia Subsystem (IMS) network is the main and basic controller for VoLTE calls; it is IMS that recognizes the approperiate conditions desired for voice traffic. The IMS network gives instructions to the LTE network using the Session 
Initiation Protocol (SIP) to create the required QoS environment and establishes the VoLTE call; it also directs LTE network to finish the special voice environment when the call is terminated [9].

\section{A. IMS Core Network Archeticture}

VoLTE is built mainly on two independent 3GPP standards: IP Multimedia Subsystems (IMS) and LTE; the first introduced in 3GPP UMTS Release 5, and the second introduced afterwards in 3GPP Release 8, meaning that both of them don't arise together, which explains the lack of dependence of each of them on the other, but VoLTE can be considered the process that created the harmony between IMS and LTE, to create the proper circumstances for supporting high quality voice service. IMS consists of many separate Nodes as shown in Fig.2

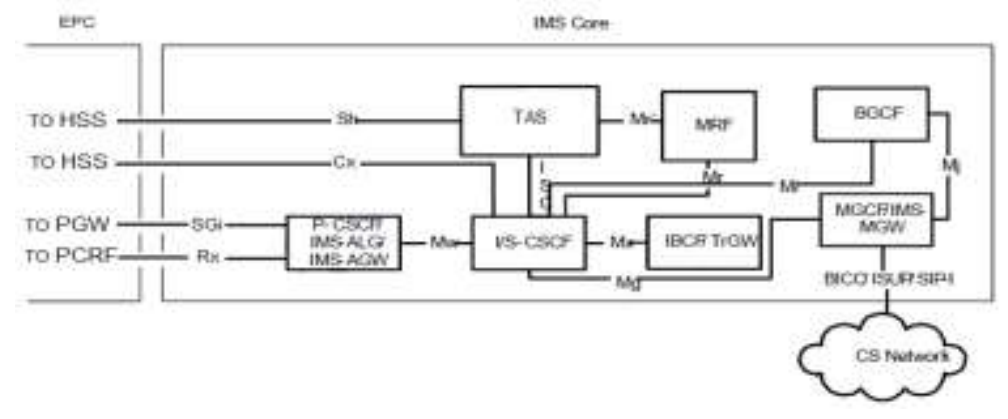

Fig. 2: IMS Core Network Architecture. Reproduced from [10]

Among these nodes there are [10]:

- Proxy Call Session Control Function (P-CSCF) behaves like SIP proxy via forwarding SIP messages among the UE and the IMS Core Network in both directions.

- Interrogating Call Session Control Function (I-CSCF) When UE performs registration with IMS, it interrogates the Home Subscriber Server (HSS) to know which S-CSCF it should route the request for registration, and during the mobile terminating calls (MTC) it interrogates the HSS to find which S-CSCF the user is registered on.

- Serving Call Session Control Function (S-CSCF) that plays the role of a SIP registrar for UEs that the HSS and I-CSCF assign to it it providing session setup, session tear-down, session control and routing functions.

- Telephony Telephony Application Server (TAS) acting as voice application server.

\section{B. VoLTE}

LTE networks with VoLTE implementation are usually have two default bearers and one dedicated bearer, each default bearer has its own IP address and connected to a different Packet Data Network (PDN), default bearer \#1 is attached to the IMS network for signaling and default bearer \#2 is attached to any internet network (including public Internet) for applications like browsing, chatting, email, etc. While the dedicated bearer is for the VoLTE traffic delivering, thus, linked to default bearer \#1. Table 1 shows list of different VoLTE bearers and related specifications. 
Table 1: VoLTE Bearers Specifications

\begin{tabular}{|l|l|l|l|}
\hline \multirow{2}{*}{ Property } & \multicolumn{3}{|c|}{ VoLTE Bearer types } \\
\cline { 2 - 4 } & \multicolumn{1}{|c|}{ Default \#1 } & \multicolumn{1}{c|}{ Default \#2 } & \multicolumn{1}{c|}{ Dedicated } \\
\hline Carried data & $\begin{array}{l}\text { SIP signaling } \\
\text { with IMS } \\
\text { network }\end{array}$ & $\begin{array}{l}\text { All other } \\
\text { internet } \\
\text { traffic }\end{array}$ & VoLTE traffic \\
\hline IP address & $\begin{array}{l}\text { specific } \\
\text { address }\end{array}$ & $\begin{array}{l}\text { specific } \\
\text { address }\end{array}$ & $\begin{array}{l}\text { linked to } \\
\text { Default \#1 }\end{array}$ \\
\hline QCI value & 5 & 9 & 1 \\
\hline Priority & 1 & 9 & 2 \\
\hline $\begin{array}{l}\text { Max. delay } \\
\text { (ms) }\end{array}$ & 100 & 300 & 100 \\
\hline $\begin{array}{l}\text { Packet loss } \\
(\%)\end{array}$ & $10-6$ & $10-6$ & $10-2$ \\
\hline
\end{tabular}

\section{OTT VoIP}

OTT refers to services provided independently by 3rd party over the mobile operators' services, like "Skype", "Viber" and "Google Talk", etc. Many OTT VolP applications also include rich communication features such as making video calls, sharing files, and chating.

OTT VoIP over LTE handling and treatment is based on both LTE network and the generic IP network (The Public Internet), where in LTE the OTT VoIP over LTE data streams are treated like other IP data streams, all are transfered over the default bearer according to 3GPP, [11] therefore all OTT VoIP applications don't provide QoS because of the fact that the same way is used for all IP data traffic; real-time voice/video communication, web browsing, file downloading/ uploading and audio/video streaming, etc., hence it is exactly like any other type of data packet, in other words, all are treated as best effort, thus, packets for voice doesn't have any advantage over any other packets; there is no reservation for bandwidth nor allocating of priority levels, accordingly there are no rules for QoS parameters like delay, jitter, and packet loss. In addition to LTE network there is the Internet network negative impact, since OTT VoIP calls may have to be routed through PGW to the public Internet while contacting the VolP service provider's infrastructure, making these QoS parameters getting worse. Although LTE network operators "can create natural convenience for the development of OTT VoIP calls" and break almost all the barriers, by using its features like broad bandwidth, low latency, being always-online, [11] even if it was applied, the QoS of the Internet network will remain then nonguaranteed.

\section{IV.SIMULATION}

Since both VoLTE and OTT VoIP are VoIP packets, this was the main purpose for the previous explanation for the difference between both of them and nothing was left but evaluating the performance for each of them to get a valid perception and indication then a correct prediction for the difference in the quality for each of them if implemented in LTE network.

This section includes details of OTT VoIP performance compared with VoLTE in presence of simulation graphs based on simulation for QoS parameters such as End- 
to-End Delay, Packet Delay Variation (PDV), Jitter, Packet Loss (PL) in addition to Mean Opinion Score (MOS), all using OPNET 17.5 simulation software.

According to 3GPP, it is mandatory to use voice codecs of Adaptive Multi-Rate Narrow Band (AMR-NB) family at least for VoLTE, [12] but Since the voice quality depends on the audio codec used as well as network-level factors such as End-to-End Delay, jitter, Packet Delay Variation (PDV) and packet loss, [13] and since this study is only focused on the QoS parameters, therefore in VoLTE and OTT VoIP simulation the same voice codec is used, and since G.711 codec is one of the most wide-spread VolP codecs used in the market, so it will be applied for VoLTE in addition to OTT VolP as well.

\section{A. Network Topology In OPNET}

LTE network is built in OPNET 17.5 as following:

- LTE network is created to be consisted of two cells, the Evolved Packet Core (EPC) and different number of User Equipment's (UEs) according to the scenario, along with application models like voice and FTP.

- The used IMS model exist at the contributed models section available in [14] it consists of proxy, serving and interrogating call session control functions (P/l/SCSCF) which are responsible for signaling procedures for the VoLTE users.

- SIP proxy server (virtually inside the public Internet network) representing a part of VolP service provider's infrastructure that is used for supporting the OTT VoIP service signaling.

- An FTP server that the users will use for downloading files.

\section{B. Simulation Scenarios In OPNET}

The performance of OTT VoIP and VoLTE will be investigated during two cases; the first case while the network is congested and the second case while the network is in non-congested state, each case will be executed twice, first time with users making calls using VoLTE and the second with users making calls with OTT VoIP.

1) The first case (network is congested): Four different scenarios are considered depending on the number of users as following: scenario 1 with 5 users/cell, scenario 2 with 10 users/cell, scenario 3 with 15 users/cell and scenario 4 with 20 users/cell, all users in each scenario are downloading 1 Megabytes file through the FTP server, during simulation, users will start the file downloading around the 100th second; causing congestion to the network in each scenario, typically at the 3rd minute (180th second) the Voice conversations will start between users at cell 1 (Callers) and users at cell 2 (Callees), therefore it will be 5 users/cell in scenario 1 and also 5 voice conversations and in scenario 2 we will have 10 voice conversations ,etc. It shall be noted that, for all scenarios simulation period is 8 minutes and in VoLTE simulation, a gold bearer is chosen, with a 96 Kbps link bitrate in downlink and uplink.

The built LTE network topology and scenarios are as shown in Fig. 3.
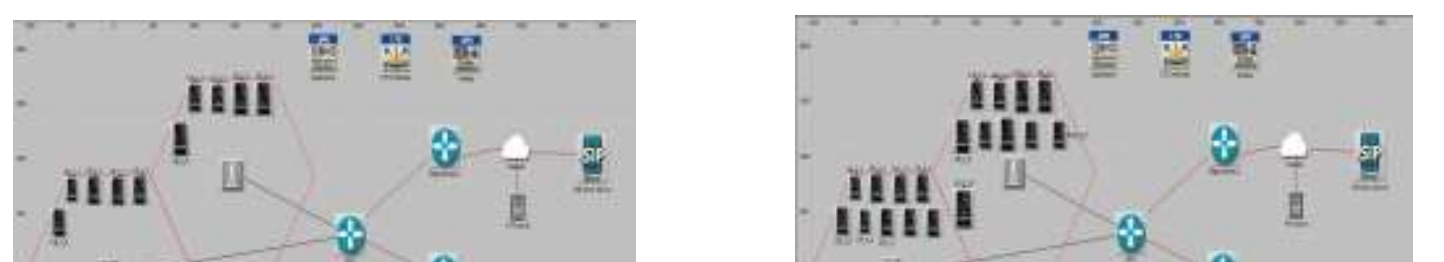
(b)

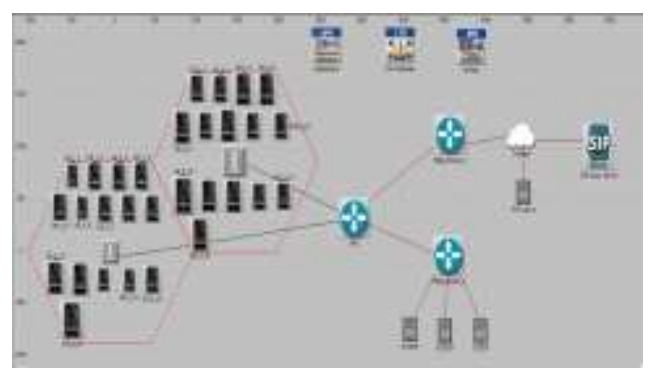

(a)

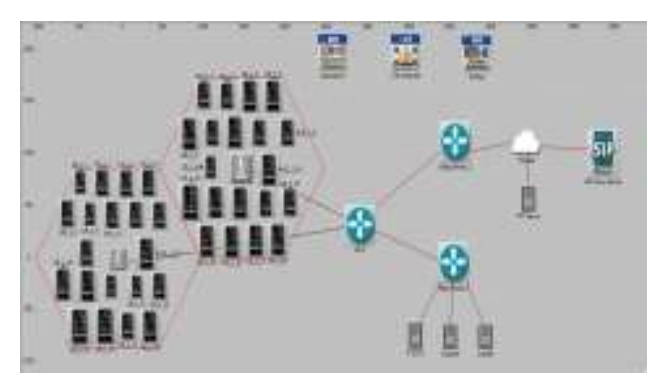

(c)

(d)

Fig. 3: Simulates LTE network topology and simulation scenarios in OPNET. (a) scenario 1, (b) scenario 2, (c) scenario 3, (d) scenario 4

2) The second case (network is non-congested): Where the users handles only voice and there is no file downloading i.e. only voice traffic is generated in the network, the number of voice calls in the network is growing periodically from the 3rd minute to the 10th minute and half (650 seconds) with 1 voice call added every 30 seconds, this case will be executed two times also, one time with VoLTE voice calls and the other with OTT VoIP voice calls.

\section{LTE Settings In OPNET}

Entire LTE network is modeled following attributes values, and links listed in Table 2 and Table 3.

Table 2: LTE Network Links in OPNET

\begin{tabular}{|c|c|}
\hline \multicolumn{2}{|c|}{ LTE Network Links } \\
\hline Link & Type \\
\hline eNodeB-EPC & PPP_DS \\
\hline EPC - Edge_router_1 & 1 \\
EPC - Edge_router_2 & 1000Bas \\
Internet - FTP Server & eX \\
Internet - SIP Proxy & \\
Server & \\
\hline
\end{tabular}




\begin{tabular}{|c|c|}
\hline \multicolumn{2}{|c|}{ LTE Network Links } \\
\hline Link & Type \\
\hline Edge_router_2 - Internet & \\
Edge_router_2 - (P/I/S- \\
CSCF)
\end{tabular}

Table 3: LTE Network Settings in OPNET

\begin{tabular}{|c|c|c|}
\hline \multicolumn{3}{|c|}{ LTE Network Settings } \\
\hline Node & Attribute & Value \\
\hline \multirow{6}{*}{ UE } & Antenna gain $(\mathrm{dBi})$ & $-1 \mathrm{dBi}$ \\
\hline & MCS Index & 28 \\
\hline & $\begin{array}{l}\text { Pathloss } \\
\text { Parameters }\end{array}$ & Free space \\
\hline & Receiver Sensitivity & $-200 \mathrm{dBm}$ \\
\hline & $\begin{array}{l}\text { Number of } R x \\
\text { Antennas }\end{array}$ & 2 \\
\hline & $\begin{array}{l}\text { Number of Tx } \\
\text { Antennas }\end{array}$ & 1 \\
\hline \multirow{8}{*}{$\begin{array}{l}\text { eNode } \\
\text { B }\end{array}$} & Antenna Gain (dBi) & $15 \mathrm{dBi}$ \\
\hline & PHY Profile & 1.4 MHZ FDD \\
\hline & $\begin{array}{l}\text { MIMO Transmission } \\
\text { Technique }\end{array}$ & $\begin{array}{l}\text { Spatial } \\
\text { Multiplexing } 2 \\
\text { Codewords } 2 \\
\text { Layers }\end{array}$ \\
\hline & $\begin{array}{l}\text { Number of } \mathrm{Rx} \\
\text { Antennas }\end{array}$ & 2 \\
\hline & $\begin{array}{l}\text { Number of Tx } \\
\text { Antennas }\end{array}$ & 2 \\
\hline & Operating Power & 20 \\
\hline & Receiver Sensitivity & $-200 \mathrm{dBm}$ \\
\hline & Scheduling Mode & $\begin{array}{l}\text { No Link } \\
\text { Adaptation }\end{array}$ \\
\hline & & \\
\hline
\end{tabular}

\section{SimULATION RESULTS}

The resulted graphs compare QoS parameters such as End to End Delay, Packet Delay Variation (PDV), Jitter and Packet Loss (PL)) in addition to Mean Opinion Score (MOS) between VoLTE and OTT VoIP for the whole scenarios while the mean value of each QoS parameter is considered in each scenario.

\section{A. First Case Results}

1) Packet End-to-End delay: This parameter gives the total voice packet delay i.e. the mouth to ear delay between the users. In all scenarios, the aggregate mean End-to-End delay for all users in each scenario in the network is considered, the End-to-End delay for VoLTE as shown in the graph in Fig. 4 has almost the same value for 5 Users/cell (scenario 1) where the value is [0.084 sec] and 10 
Users/cell (scenario 2) where the value is [0.099sec] with small increase at 15 Users/cell (scenario 3) to be [0.130 sec] which lies in the Good Quality VolP region according to VolP Quality classification with respect to the End-to-End Delay values provided in [15] and summarized in Table 4 below, but in scenario 4 (20 Users/cell) the value exceeds that limit to be [0.232 sec] which lies in the Acceptable Quality VolP region.

Table 4: VolP Quality classification according to the End-to-End Delay values

\begin{tabular}{|l|l|l|l|}
\hline VolP Quality & Good & $\begin{array}{l}\text { Acceptab } \\
\text { le }\end{array}$ & Poor \\
\hline $\begin{array}{l}\text { End-to-End Delay } \\
\text { (ms) }\end{array}$ & $0-150$ & $150-300$ & $\begin{array}{l}>30 \\
0\end{array}$ \\
\hline
\end{tabular}

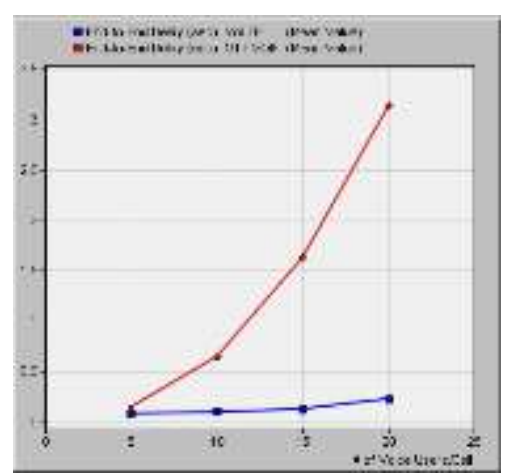

Fig. 4: End to End Delay vs. No. of Voice Users/cell

In contrast the End to End delay for OTT VoIP lies in the Acceptable Quality VoIP region in scenario 1 only $(0.152 \mathrm{sec})$ while the other three scenarios lie in the Poor Quality VolP region with values $0.652,1.632,3.13 \mathrm{sec}$ for scenarios 2, 3,4 respectively.

2) Packet Delay Variation (PDV): This parameter gives measures to the variance among End to End delays for voice packets. In all simulations, for all the users in the network, the aggregate mean PDV values in each scenario is considered, as shown in the graph in Fig. 5 the PDV for VoLTE has almost the same value for scenario 1 where the value is $[0.0001 \mathrm{sec}]$ and scenario 2 where the value is [0.0003sec] with slight increase in scenario 3 to be $[0.015 \mathrm{sec}]$ but in scenario 4 the value is severe [1.845sec]. On the other hand the PDV values for OTT VolP are very severe with values $0.961,0.652,1.632,3.13 \mathrm{sec}$ for scenarios $1,2,3,4$ respectively. 


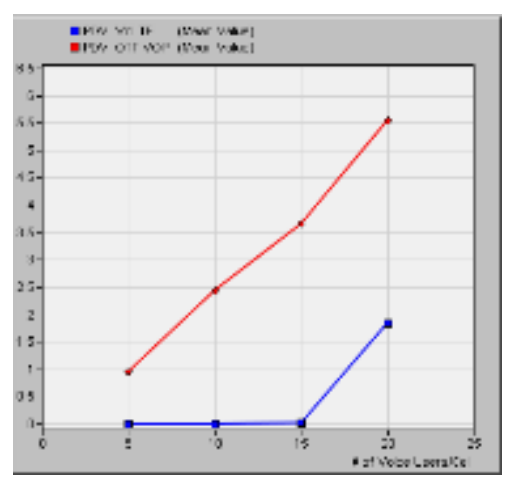

Fig. 5: PDV vs. No. of Voice Users/cell

3) Jitter: VolP Quality regions versus the Jitter values are given in Table $V$ below (15). The Jitter graph is shown in fig. 6; the Jitter for VoLTE lies in the good VolP quality at scenario 1,2 and 3 with values less than $20 \mathrm{msec}$, but it is acceptable VolP quality in scenario 4 with value $27 \mathrm{msec}$. On the other hand the jitter values for OTT VoIP are acceptable only for scenario 1 and poor for the other scenarios..

Table 5: VoIP Quality classification according to jitter values

\begin{tabular}{|l|l|l|l|}
\hline VolP Quality & Good & $\begin{array}{l}\text { Acceptab } \\
\text { le }\end{array}$ & Poor \\
\hline Jitter (ms) & $0-20$ & $20-50$ & $>50$ \\
\hline
\end{tabular}

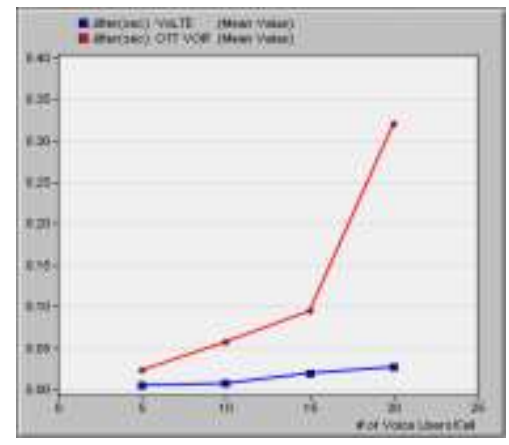

Fig. 6: Jitter vs. No. of Voice Users/cell

4) Mean Opinion Score (MOS): MOS is a measure of the Quality of Experience for VolP users, it is the most important Key Performance Indicator (KPI) used for VolP service QoS evaluation [16]. The E-Model defined in [17] is used to calculate the MOS based on the Rating Factor or R-factor. The R-factor is used to identify the quality of the VoIP. The OPNET software uses the same concept to calculate the MOS value which is mapped to the level of satisfaction of the end users based on ITU-T P.800 [18] and shown in Table 6 that shows MOS values and the correspondent QoS perception of a call by end users. The MOS graph is shown in Fig. 7.

Table 6: MOS Values and QoS perception by end user 


\begin{tabular}{|c|c|}
\hline $\begin{array}{c}\text { MOS } \\
\text { value }\end{array}$ & $\begin{array}{c}\text { Quality of VolP } \\
\text { call }\end{array}$ \\
\hline 5 & Excellent \\
\hline 4 & Good \\
\hline 3 & Fair \\
\hline 2 & Poor \\
\hline 1 & Bad \\
\hline
\end{tabular}

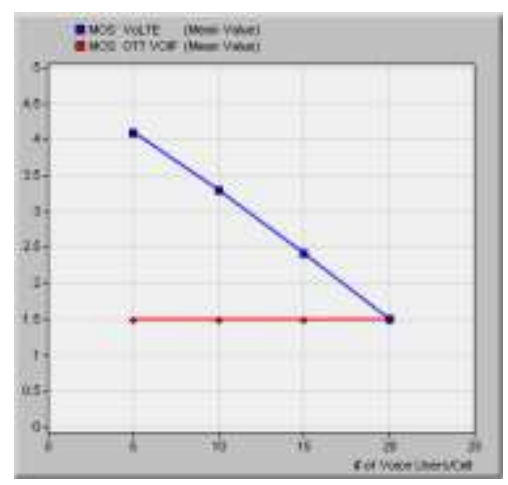

Fig. 7: MOS vs. No. of Voice Users/cell

5) Packet Loss (PL): The packet loss gives the percentage of VolP packets that are dropped by network due to congestion at the EPC node. Packet Loss (PL) is calculated with the following formula:

$$
P L=[(\text { Packet sent-Packet received }) / \text { Packet sent }]^{\star} 100 \%
$$

VolP Quality regions versus the Packet Loss values are given in Table 7 [15]. The Packet Loss (PL) is shown in fig. 8 where the OTT VolP always exceeds the packet loss percentage value of $1.5 \%$ for the poor VolP quality with large values $(2.47,6.2,7.43$ and $11.22 \%)$. VoLTE lies in the good VolP quality at scenario 1 , 2 and 3 with values around $0.01 \%$ as specified in (16 for $\mathrm{QCl}$ ) in scenarios 1 and 2 but in scenario 3 with value $0.04 \%$, but with value $8.5 \%$ in scenario 4 with very poor VoIP Quality.

Table 7: VolP Quality classification according to packet loss values

\begin{tabular}{|l|l|l|l|}
\hline VolP Quality & Good & $\begin{array}{l}\text { Acceptab } \\
\text { le }\end{array}$ & Poor \\
\hline Packet Loss & $0-0.5 \%$ & $\begin{array}{l}0.5 \%- \\
1.5 \%\end{array}$ & $>1.5 \%$ \\
\hline
\end{tabular}




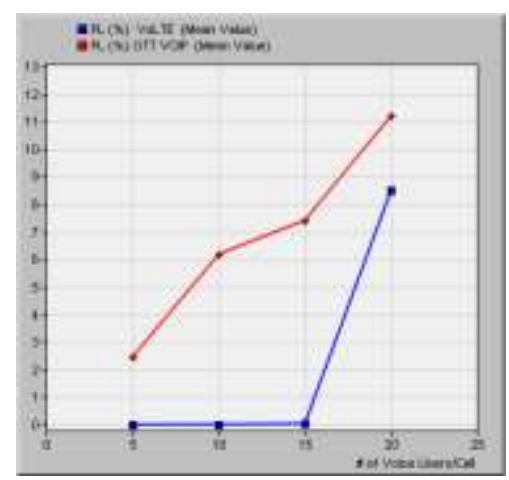

Fig. 8: PL vs. No. of Voice Users/cell

\section{B. Second Case Results}

For this case, the Packet End-to-End delay, Packet Delay Variation (PDV), Jitter, MOS and Packet Loss (PL) are shown in Fig. 9 with respect to simulation time. The resulted graphs show that values are almost the same for both OTT VoIP and VoLTE.
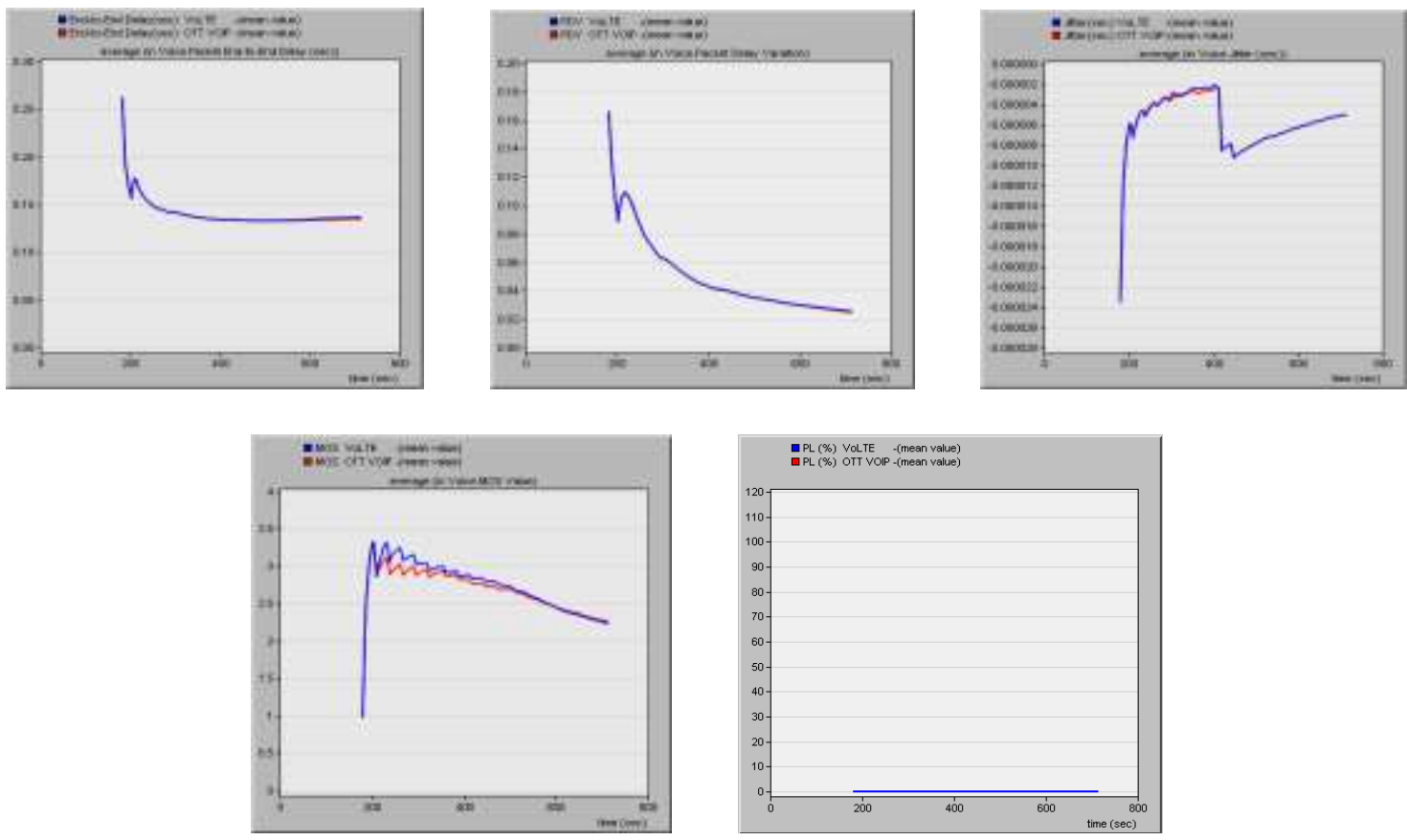

Fig. 9: Simulation graphs with respect to simulation time. (a) End-to-End delay, (b) PDV, (c) Jitter, (d) MOS, (e) PL

\section{CONCLUSION}

This paper provided a simulation platform to evaluate end-to-end QoS of OTT VoIP over LTE compared with VoLTE, based on OPNET Modeler. First case of simulation focused on the network while in congestion state, four different scenarios that represent four different congestion levels are considered, the simulation graphs in this case showed the negative impact of congestion on the performance of OTT VoIP and the superiority of performance of VoLTE to overcome the congestion state to a great extent.VoLTE had a good immunity against network congestion. Result graphs in 
second case of simulation showed that, the incremented voice calls have almost the same results for OTT VoIP and VoLTE.

\section{REFERENCES}

[1] Mohamed Hassan Babiker and Hala Eldaw Idris, "Throughput Performance Analysis VOIP over LTE," IOSR Journal of Electronics and Communication Engineering (IOSR-JECE), vol. 11, Issue 1, ver. I, pp. 15-23, Jan. - Feb. 2016.

[2] H. Holma and A. Toskala, LTE for UMTS: Evolution to LTE-Advanced, 2nd ed. Books.google.com, 2011, p. 373.

[3] Vaishali Paisal. "Seamless voice over LTE", Internet Multimedia Services Architecture and Application(IMSAA), 2010 IEEE 4th International Conference on, On page(s): 1-5

[4] Adnan Basir (2012, May 12). Voice solutions in LTE. [online]. Available: http:// 4gIte-world.blogspot.com.

[5] Thushara Weerawardane, Optimization and Performance Analysis of High Speed Mobile Access Networks, 1st ed. Books.google.com, 2012, p.41

[6] Zeeshan Kaleem, Bing Hui, KyungHi Chang, "QoS priority-based dynamic frequency band allocation algorithm for load balancing and interference avoidance in 3GPP LTE HetNet," in EURASIP Journal on Wireless Communications and Networking, 2014. DOI: 10.1186/1687-1499-2014-185

[7] Policy and charging control architecture, 3GPP Technical Secification TS 23.203 V8.9.0, 2010

[8] "A Review on Voice over Internet Protocol (VOIP) over LTE Networks", International Journal of Science, Engineering and Technology Research (IJSETR), vol. 5, Issue 5, pp. 1527-1531, May 2016.

[9] An Industry Whitepaper. (2015). Voice over LTE: Challenges and Opportunities (Version 2.0) [Online]. Available FTP: www.sandvine.com File: volte-challengesand-opportunities.pdf

[10] VoLTE Service Description and Implementation Guidelines, GSMA standards Version 1.1, 26 March 2014

[11]Chen Qunhui. (2011). Evolution and Deployment of VoLTE [online]. Available FTP: http://www1.huawei.com File: hw-094164.pdf.

[12]A. Vizzarri. "Analysis of VoLTE End-To-End Quality of Service using OPNET", Modelling Symposium (EMS), 2014 European, On page(s): 452 - 457

[13] S Ganguly and S Bhatnagar, VolP: Wireless, P2P and New Enterprise Voice over IP, 1st ed. Books.google.com, 2008, p.41.

[14] Enrique Vazquez. (2013). SIP in the 3GPP IP Multimedia Subsystem (IMS) Extension [online]. Available FTP: https://splash.riverbed.com File: sip-imsmodel.1012.zip

[15] James Yu and Imad Al Ajarmeh, "Design and Traffic Engineering of VolP for Enterprise and Carrier Networks," The International Journal On Advances in Telecommunications, pp. 27-39, 2008

[16] LTE; Telecommunication management; Key Performance Indicators (KPI) for the Evolved Packet Core(EPC), ETSI TS 132455 V10.0.0, 2011

[17] The E-Model, a computational model for use in transmission planning, ITU-T Recommendation G.107, 2011.

[18]Methods for subjective determination of transmission quality, ITU-T Recommendation P.800, 1996. 
